\title{
Exposure to wireless phone emissions and serum B-trace protein
}

\author{
LENNART HARDELL $^{1}$, FREDRIK SÖDERQVIST ${ }^{1}$, MICHAEL CARLBERG ${ }^{1}$, \\ HENRIK ZETTERBERG ${ }^{2}$ and KJELL HANSSON MILD ${ }^{3}$
}

\author{
${ }^{1}$ Department of Oncology, University Hospital, SE-701 85 Örebro; ${ }^{2}$ Institute of Neuroscience and Physiology, Department \\ of Psychiatry and Neurochemistry, the Sahlgrenska Academy at the University of Gothenburg, Sahlgrenska University \\ Hospital/Mölndal, SE-431 80 Mölndal; ${ }^{3}$ Department of Radiation Sciences, Umeå University, SE-901 87 Umeå, Sweden
}

Received March 31, 2010; Accepted April 29, 2010

DOI: 10.3892/ijmm_00000466

\begin{abstract}
The lipocalin type of prostaglandin D synthase or ß-trace protein is synthesized in the choroid plexus, leptomeninges and oligodendrocytes of the central nervous system and is secreted into the cerebrospinal fluid. $\beta$-trace protein is the key enzyme in the synthesis of prostaglandin D2, an endogenous sleep-promoting neurohormone in the brain. Electromagnetic fields (EMF) in the radio frequency (RF) range have in some studies been associated with disturbed sleep. We studied the concentration of $\beta$-trace protein in blood in relation to emissions from wireless phones. This study included 62 persons aged 18-30 years. The concentration of $\beta$-trace protein decreased with increasing number of years of use of a wireless phone yielding a negative $\beta$ coefficient $=$ $-0.32,95 \%$ confidence interval -0.60 to -0.04 . Also cumulative use in hours gave a negative $B$ coefficient, although not statistically significant. Of the 62 persons, 40 participated in an experimental study with $30 \mathrm{~min}$ exposure to an $890-\mathrm{MHz}$ GSM signal. No statistically significant change of $\beta$-trace protein was found. In a similar study of the remaining 22 participitants with no exposure, $\beta$-trace protein increased significantly over time, probably due to a relaxed situation. EMF emissions may down-regulate the synthesis of B-trace protein. This mechanism might be involved in sleep disturbances reported in persons exposed to RF fields. The results must be interpreted with caution since use of mobile and cordless phones were self-reported. Awareness of exposure condition in the experimental study may have influenced Btrace protein concentrations.
\end{abstract}

\section{Introduction}

The lipocalin type of prostaglandin D synthase (L-PGDS) plays a crucial role in sleep promotion. L-PGDS is mainly synthesized in the choroid plexus, leptomeninges (pia-arachnoid

Correspondence to: Professor Lennart Hardell, University Hospital, SE-701 85 Örebro, Sweden

E-mail: lennart.hardell@orebroll.se

Key words: B-trace protein, cordless phones, mobile phones, prostaglandin D synthase, radio frequency fields, sleep disurbance membrane) and oligodendrocytes of the central nervous system (CNS). It is secreted into the cerebrospinal fluid (CSF) as $\beta$-trace $(1,2)$. L-PGDS purified from human CSF and $B-$ trace are structurally, enzymatically and immunologically identical (3).

B-trace is the second most abundant protein in CSF after albumin, representing $8 \%$ of all CSF protein (2). The concentration in CSF is 32-times higher than in serum, which indicates that serum $\beta$-trace originates predominantly from CNS (4). Small quantities of $\beta$-trace are found in closed compartments outside the brain, such as testis, retina and cochlea, but can not influence serum $B$-trace (5). There is a continous release of $\beta$-trace into CSF and by the CSF flow into the blood stream. The half-life time has been calculated to $4 \mathrm{~h}$ in the blood (6).

B-trace has a circadian pattern, increasing in the evening with the highest concentration at night, and regulates sleep through the prostaglandin D system (7). Prostaglandin $\mathrm{D}_{2}$ $\left(\mathrm{PGD}_{2}\right)$ is present in relatively high concentration in the brain. $\beta$-trace is the key enzyme in the synthesis of $\mathrm{PGD}_{2}$, which is an endogenous sleep-promoting neurohormone (8). The action of $\mathrm{PGD}_{2}$ is mediated by a specific prostanoid receptor, the DP receptor. This receptor is localized in the chemosensory region of the ventromedial surface of the rostral basal forebrain (9). The signal to initiate sleep is initiated via adenosine A2A receptive neurons (10). This results in the activation of a cluster of neurons in the sleep center within the ventrolateral preoptic area (11).

During recent years the prevalence of disturbed sleep has increased in the Swedish population. Thus, sleep problems were twice as common in 2003 compared with 1993, increasing from $10-12 \%$ to $20-24 \%$ of the population. Among adolescents in Sweden it was three to four times more common in 2003 compared with 1993. The reasons for this are unknown, although life style, school- and work-related factors probably are involved with increasing demands on the individual (12-14).

The use of wireless phones has become an essential part of modern life. There is a general concern about potential health effects of exposure to electromagnetic fields (EMF) in the radiofrequency $(\mathrm{RF})$ range from these devices, both mobile phones and cordless desktop phones (DECT). Since the phones are used in close proximity to the head, EMF emitted from these phones result in considerably higher exposure to the brain than to other organs (15). An increased risk for brain 
tumours has been indicated in some studies, for overview see Hardell et al (16). Self-reported symptoms include e.g. headache, fatigue, dizziness, skin sensations, cognitive symptoms and sleep-disturbances $(17,18)$.

Exposure to pulse-modulated EMF affected human EEG in several studies according to the Independent Expert Group of the Swedish Radiation Safety Authority (19). It also affected the sleep EEG during night-time sleep (20) and prior to daytime sleep (21). In a follow-up study pulse-modulated EMF altered waking regional cerebral blood flow. Also waking and sleep EEG was changed, and pulse modulation of EMF was necessary to induce these effects (22). A GSM-handsetlike signal affected non-REM sleep EEG in a dose-response relation with the applied SAR ranging from 0.2 to $5 \mathrm{~W} / \mathrm{kg}$ (23). Additionally, components of sleep were affected in an experimental study of $884 \mathrm{MHz}$ GSM wireless communication signals. After $3 \mathrm{~h}$ average $1.4 \mathrm{~W} / \mathrm{kg}$ exposure there was a prolonged latency to reach the first cycle of deep sleep (stage 3) and the amount of stage 4 sleep was decreased (24). In another experimental study the 'talk-mode' signals of a GSM 900 mobile phone delayed EEG-determined sleep onset (25). This has been reviewed elsewhere $(26,27)$. Additionally, sleep disturbances have been reported among inhabitants around mobile phone base stations $(28,29)$.

Since EMF emissions from mobile phones might affect sleep and B-trace is a sleep-promoting neurohormone it was of interest to also analyse that protein in our experimental study on exposure to a GSM signal (30). The study was approved by the regional ethics committee.

\section{Materials and methods}

In the first part of this study 44 volunteers aged 18-30 years were recruited from the municipality of Umeå, Sweden (30). Of these, 35 were randomly recruited from the population registry and 9 by personal invitation at the Department of Radiation Sciences, Umeå University, Sweden. They were asked to answer a questionnaire on e.g. use of mobile phones and cordless phones and some health and life-style related factors. The final sample consisted of 40 persons since one woman was excluded because of pregnancy, another due to loss of blood pressure during blood sampling and a third and a fourth could not participate for technical reasons in the statistical pair-wise analyses. Exposure was to an $890 \mathrm{MHz}$ GSM signal as described previously $(30,31)$. A specific absorption rate $\left(\mathrm{SAR}_{1 \mathrm{~g}}\right)$ of $1.0 \mathrm{Watt} / \mathrm{kg}$ to the temporal area was applied.

Blood was drawn on four occasions; the first 10-15 min after arrival to the hospital, the second after $30 \mathrm{~min}$ rest including study information and just before the mobile phone exposure, the third immediately after 30 min exposure, and the fourth $60 \mathrm{~min}$ after ending of the exposure. Serum was frozen for later analysis.

Addionally 22 volunteers, 11 of each sex, 18-30 years of age were recruited separately and the pre-analytical stability of $\beta$-trace was tested in that group. They were all inhabitants of the municipality of Örebro in Sweden. All answered the same questionnaire as the 40 subjects in the experimental study. This was not intended to be part of the experimental study as a control group, but to analyse the stability of the investigated proteins in relation to time to freezing of the blood sample. No microwave exposure was given during this stability test, although all other conditions were similar to the real exposure situation. Blood was drawn at the same time intervals as in the exposure study, but two samples instead of one were taken on the first two occasions. One sample (the asample) was handled in the same way as in the exposed material, while the other was centrifuged and frozen immediately after blood was drawn (the b-sample). There was no statistically significant difference of the results for the a- and b-samples, so in the following analyses the a-samples were used. All participating persons were healthy with no use of drugs. Informed consent including storing of the blood in a Biobank was given by all subjcets.

Analysis. B-trace protein was determined by an immunonephelometric assay on a BN ProSpec (Dade Behring Marburg $\mathrm{GmbH}$, Marburg, Germany) according to the instruction manual. All subjects were assigned a code number so that no personal identification was known during the analyses that were performed at the Neurochemistry Laboratory, Sahlgrenska University Hospital/Mölndal, in Sweden. All results are expressed in $\mathrm{mg} / \mathrm{l}$.

Statistical methods. Frequency tables were produced and explanatory factors were analyzed by t-test and ANOVA. Linear regression, adjusted for age, was used to test an association between long-term trends in wireless phone use and serum concentrations of $\beta$-trace. For all these analyses the first serum sample (sample 1) was used, since the condition for drawing that blood sample was similar for all study subjects. Standardized B coefficients were used throughout.

The four blood samples in the exposure and stability studies were compared using repeated measures ANOVA with Huynh-Feldt correction followed by linear contrasts for pairwise comparisons between sample 1 and sample 2, sample 2 and sample 3 , sample 3 and sample 4 . Since these a priori chosen comparisons did not exceed the degress of freedom between samples no multiple comparison adjustments were performed. All analyses were done using StataSE 10.1 (Stata/ SE 10.1 for Windows; StataCorp., College Station, TX).

\section{Results}

No statistically significant difference of B-trace protein was found between men $(n=28)$ and women $(n=34)$, Table I. The median age was 24 years and somewhat higher concentration was found in the younger subjects $(\mathrm{P}=0.049)$. Regarding time for drawing blood (morning or afternoon), weekday or month no statistically significant differences were found.

A negative standardized $\beta$ coefficient was calculated for cumulative use in hours of both mobile phones and cordless phones, however not statistically significant, Table II. Also for years since first use (latency) a negative coefficient was found, statistically significant for mobile and cordless phones combined $(\mathrm{P}=0.03)$.

In the exposure study there were no statistically significant differences between the different samples, Table III. However, in the stability study highest mean and median concentrations were found in samples 3 and 4, Table IV. The concentration 
Table I. Descriptive data for ß-trace protein $(\mathrm{mg} / \mathrm{l})$.

\begin{tabular}{|c|c|c|c|c|c|c|}
\hline & $\mathrm{n}$ & Mean & Median & Min & $\operatorname{Max}$ & P-value \\
\hline B-trace sample 1 , total & 62 & 0.524 & 0.521 & 0.345 & 0.715 & \\
\hline Gender & & & & & & 0.74 \\
\hline Men & 28 & 0.528 & 0.528 & 0.345 & 0.652 & \\
\hline Women & 34 & 0.520 & 0.512 & 0.378 & 0.715 & \\
\hline Age (cut-point at median in the whole material) & & & & & & 0.049 \\
\hline$\leq 24$ years & 33 & 0.543 & 0.542 & 0.345 & 0.715 & \\
\hline$>24$ years & 29 & 0.501 & 0.498 & 0.368 & 0.652 & \\
\hline Time (h) for drawing blood & & & & & & 0.34 \\
\hline 08:00-12:00 & 35 & 0.533 & 0.532 & 0.384 & 0.649 & \\
\hline $12: 01-15: 00$ & 27 & 0.512 & 0.509 & 0.345 & 0.715 & \\
\hline Day for drawing blood & & & & & & 0.73 \\
\hline Monday & 10 & 0.512 & 0.514 & 0.378 & 0.652 & \\
\hline Tuesday & 17 & 0.505 & 0.498 & 0.368 & 0.609 & \\
\hline Wednesday & 12 & 0.528 & 0.516 & 0.390 & 0.715 & \\
\hline Thursday & 19 & 0.539 & 0.548 & 0.345 & 0.647 & \\
\hline Friday & 4 & 0.549 & 0.524 & 0.498 & 0.649 & \\
\hline Month for drawing blood & & & & & & 0.20 \\
\hline March & 9 & 0.504 & 0.527 & 0.390 & 0.588 & \\
\hline April & 15 & 0.486 & 0.494 & 0.345 & 0.622 & \\
\hline May & 16 & 0.552 & 0.551 & 0.400 & 0.715 & \\
\hline November & 8 & 0.547 & 0.545 & 0.378 & 0.647 & \\
\hline December & 14 & 0.531 & 0.516 & 0.437 & 0.652 & \\
\hline
\end{tabular}

${ }^{\mathrm{a}}$-test for gender, age and time (h) for drawing blood, ANOVA for day for drawing blood and month for drawing blood.

Table II. Linear regression analysis for serum ß-trace, cumulative and latency and long-term use of wireless phone use adjusted for age.

\begin{tabular}{|c|c|c|c|c|}
\hline Group & $\mathrm{n}$ & Standardized $ß$ coefficient & $95 \% \mathrm{CI}$ & P-value \\
\hline \multicolumn{5}{|c|}{ Cumulative use (hours), mobile phone/DECT } \\
\hline Mobile phones + DECT & 62 & -0.17 & -0.41 to 0.07 & 0.16 \\
\hline Mobile phones & 62 & -0.18 & -0.42 to 0.06 & 0.15 \\
\hline Analogue & 2 & - & - & - \\
\hline Digital & 62 & -0.17 & -0.41 to 0.07 & 0.17 \\
\hline UMTS & 16 & -0.38 & -0.88 to 0.11 & 0.12 \\
\hline DECT & 51 & -0.08 & -0.36 to 0.19 & 0.54 \\
\hline \multicolumn{5}{|c|}{ Years since first use, mobile phone/DECT } \\
\hline Mobile phones + DECT & 62 & -0.32 & -0.60 to -0.04 & 0.03 \\
\hline Mobile phones & 62 & -0.24 & -0.54 to 0.06 & 0.11 \\
\hline Analogue & 2 & - & - & - \\
\hline Digital & 62 & -0.21 & -0.50 to 0.08 & 0.16 \\
\hline UMTS & 16 & -0.24 & -0.79 to 0.32 & 0.38 \\
\hline DECT & 51 & -0.13 & -0.42 to 0.16 & 0.38 \\
\hline
\end{tabular}


Table III. Serum concentrations of $\beta$-trace $(\mathrm{mg} / \mathrm{l})$ for all the blood samples in the exposure study and linear contrasts for a priori pairwise comparisons $(\mathrm{n}=40)$.

\begin{tabular}{|c|c|c|c|c|c|}
\hline & Mean & Median & Min & $\operatorname{Max}$ & P-value \\
\hline Repeated-measures ANOVA ${ }^{2}$ & & & & & 0.17 \\
\hline Sample 1 & 0.516 & 0.521 & 0.345 & 0.715 & \\
\hline Sample 2 & 0.521 & 0.513 & 0.370 & 0.696 & \\
\hline Sample 3 & 0.537 & 0.543 & 0.217 & 0.808 & \\
\hline Sample 4 & 0.523 & 0.521 & 0.323 & 0.685 & \\
\hline \multicolumn{6}{|l|}{ Linear contrasts } \\
\hline Sample 1 vs. Sample 2 & & & & & 0.65 \\
\hline Sample 2 vs. Sample 3 & & & & & 0.10 \\
\hline Sample 3 vs. Sample 4 & & & & & 0.15 \\
\hline Mean, sample $1+2$ vs. mean, sample $3+4$ & & & & & 0.09 \\
\hline
\end{tabular}

${ }^{2}$ Huynh-Feldt correction.

Table IV. Serum concentrations of $ß$-trace $(\mathrm{mg} / \mathrm{l})$ for all the blood samples from stability data and linear contrasts for a priori pairwise comparisons $(n=22)$.

\begin{tabular}{|c|c|c|c|c|c|}
\hline & Mean & Median & Min & $\operatorname{Max}$ & P-value \\
\hline Repeated-measures ANOVA ${ }^{3}$ & & & & & 0.0003 \\
\hline Sample 1 & 0.537 & 0.521 & 0.378 & 0.652 & \\
\hline Sample 2 & 0.554 & 0.541 & 0.365 & 0.689 & \\
\hline Sample 3 & 0.564 & 0.566 & 0.384 & 0.679 & \\
\hline Sample 4 & 0.557 & 0.545 & 0.378 & 0.701 & \\
\hline \multicolumn{6}{|l|}{ Linear contrasts } \\
\hline Sample 1 vs. Sample 2 & & & & & 0.006 \\
\hline Sample 2 vs. Sample 3 & & & & & 0.07 \\
\hline Sample 3 vs. Sample 4 & & & & & 0.24 \\
\hline Mean, sample $1+2$ vs. mean, sample $3+4$ & & & & & 0.0003 \\
\hline
\end{tabular}

${ }^{3}$ Huynh-Feldt correction.

increased from sample 1 to sample $2(\mathrm{P}=0.006)$ and increased further from sample 2 to sample $3(\mathrm{P}=0.07)$. The mean and median concentrations were higher in sample 4 than in sample 1 and sample 2, although not statistically significantly different from sample $3(\mathrm{P}=0.24)$.

We lumped together samples 1 and 2 and compared with samples 3 and 4 together. In the exposure study no statistically significant difference was found, mean sample 1 and $2=0.519$, mean sample 3 and $4=0.530(\mathrm{P}=0.09)$. In the stability study mean concentration was in samples 1 and $2=0.545$ and in samples 3 and $4=0.561$ ( $\mathrm{P}=0.0003)$ (Table IV).

\section{Discussion}

The main finding of this study was that the more years a mobile or a cordless phone had been used, the lower $\beta$-trace protein concentration in blood was found. The decrease of the concentration was statistically significant when use of mobile and cordless phones was analysed together. Also cumulative use in hours yielded decreased concentration of $\beta$-trace with a negative $\beta$ coefficient, although not statistically significant.

In the exposure study no statistically significant differences were found between the different samples. This was in contrast to the stability study where highest concentrations of B-trace protein were found in the last two samples. This difference was statistically significant. In both parts of the study highest concentrations were found in sample 3 , but in the stability study also mean and median concentrations in sample 4 were higher than in samples 1 and 2 .

These results may indicate that emissions from wireless phones affect the release of $\beta$-trace protein in the brain, primarily from the choroid plexus and the leptomeninges. Especially the leptomeninges that surround the brain close to the bone of the skull, are highly exposed to RF fields during the use of wireless phones. 
The results for long-term use and cumulative use indicate a chronic effect on the concentration of $\beta$-trace, possibly by a down-regulation of the gene. Results from the exposure study indicate that an acute effect might also be involved. After the initial insertion of a needle for the blood samples and information about the study the persons were seated in a chair and looked at a film. All persons viewed the same film on nature without any emotional stress. During this relaxation time Btrace increased statistically significantly in the stability study in contrast to the exposure study.

There are, however, some limitations in the study. First, the number of participants was rather low, especially in the stability study. Furthermore, the persons in the exposure study were aware of exposure due to the noise from the equipment during the $30 \mathrm{~min}$ exposure. In the stability study no exposure was given, so these persons might have had a more relaxed and comfortable situation compared to the exposed group. Blood was drawn at the same intervals and with the same procedure in the both groups, so it is unlikely that the differences in the results were due to blood sampling.

The results for long-term use of mobile and cordless phones were based on questionnaire data for these 62 persons in total. The questionnaires were answered before the study subjects were included in the study. It was of vital importance to assess information on potential confounders for all of the proteins analysed in this study (30). Thus, all study persons were healthy without e.g. hypertension, neurological diseases, kidney disorders, heart diseases such as angina or stenosis and thyroid dysfunction. That is diseases that may affect serum $\beta$-trace protein concentrations (32). For that reason it was of advantage to include only young persons aged 18-30 years. One disadvantage is, however, that the results can not be generalised to other age groups.

In the descriptive analysis only age predicted serum $\beta$-trace concentrations with higher concentrations in the youngest age group. The results for long-term use were consequently adjusted for age. The concentration of $B$-trace protein has a circadian rhythm coupled to the sleep - awake cycle with highest concentrations during night (32). We did not find any statistically significant differences if the first blood sample was taken in the morning or in the afternoon. Changes of the circadian rhythm with alterations of the prostaglandin D system has been shown in several diseases with hypersomnia such as African sleeping sickness (33), systemic mastocytosis (34), and severe obstructive sleep apnea syndrome (7).

Reduction of B-trace protein is a significant biological event involved in the malignant progression of astrocytoma and is predictive of poor survival (35). Significant reduction in cell proliferation and viability in the A172 glioblastoma cell line was found when $\mathrm{PGD}_{2}$ was exogenously supplied. Our findings in this study of decreased concentration of $\beta$-trace protein in serum among long-term users of wireless phones might be of interest in relation to our previous results of increased risk for astrocytoma, especially high grade, among long-term users of mobile and cordless phones $(36,37)$.

B-trace is the most common protein in liquor next to albumin. There is a high gradient to the blood since the concentration in liquor is 32 times higher. Small quantities are found in other compartments but they are closed to the blood and can not contribute to serum concentration to any substantial degree. Thus, determing serum concentrations of $\beta$-trace in relation to exposure to RF-fields is feasible to further study potential effects on sleep by such exposure.

Several studies have indicated sleep disturbances by exposure to mobile phone emissions. As discussed above both short-term effect such as EEG $(21,22)$ and latency to reach first cycle of deep sleep (24) as well as possible longterm effects e.g. sleep disturbances from emissions from base stations have been reported (28). The results in our study indicate a biological mechanism for these findings, possibly down regulation of the synthesis of $\beta$-trace protein.

Regarding long-term use our results were based on selfreporting of wireless phone use. We were not able to get verification of such use from records from different phone operators. A prospective study with individual measurement of emissions for a shorter time period would be one possibility to improve the study design. Of course a larger study sample would be worthwhile. Regarding long-term use a statistically significant negative B-coefficient was found for years since first use. It is most probable that reporting of the first year for use of mobile or cordless phone is more valid than cumulative exposure in hours over the years. The subjects were asked to report their average use in minutes per day over all years, but such use may differ from time to time. Years since first use was based on the reported first year of use of a wireless phone. For errors in recall to bias the results, such error would have to associate with B-trace levels. So, if the results suffer from recall error it is most likely non-systematic, which would dilute any association. A negative B-coefficient was also found for cumulative use, that is, the more the wireless phone was used the lower serum concentration of $\beta$-trace was found.

In respect to the exposure and stability studies each person served as his or her own control in the pairwise statistical analysis. The number of individuals especially in the stability study was low and a better study design is desirable with a randomised crossover study including sham exposure. As discussed it can not be excluded that the knowledge of being exposed made the persons in the exposure study less relaxed than in the stability study, which might have influenced ß-trace concentration. Of interest is anyhow that the results in that part of our investigation support the findings in the study of long-term use among the same persons.

In summary, this study showed a negative trend of $\beta$-trace protein concentration in serum for long-term use of wireless phones. These results might be supported by the results in our study on exposure with an $890 \mathrm{MHz}$ GSM signal that showed no statistically significant change of $\beta$-trace. This was in contrast to the results in a similar study with no exposure where $B$-trace increased significantly over time, probably due to a relaxed situation. However, in the exposure study the awareness of exposure might have biased the results although the two studies were otherwise performed under similar circumstances.

\section{Acknowledgements}

Ms Iréne Larsson participated in the data collection, David Johansson and Tony Larsson collected the blood samples. The study was supported be grants from Cancer- och Allergi- 
fonden, Cancerhjälpen and Örebro University Hospital Cancer Fund.

\section{References}

1 Kuruvilla AP, Hochwald GM, Ghiso J, Catano EM, Pizzolato M and Frangione B: Isolation and amino terminal sequence of Btrace, a novel protein from human cerebrospinal fluid. Brain Res 565: 337-340, 1991

2. Watanbe K, Urade Y, Mäder M, Murphy C and Hayaishi O: Identification of $\beta$-trace as prostaglandin D synthase. Biochem Biophys Res Commun 203: 1110-1116, 1994.

3. Hoffman A, Conradt HS, Gross G, Mimtz M, Lottspeich F and Wurster U: Purification and chemical characterization of B-trace protein from human cerebrospinal fluid: its identification as prostaglandin D synthase. J Neurochem 61: 451-456, 1993.

4. Tumani H, Nau R and Felgenhauer K: B-trace protein in cerebrospinal fluid: a blood-CSF barrier-related evaluation in neurogical diseases. Ann Neurol 44: 882-889, 1998.

5. Urade Y, Watanabe K and Hayaishi O: Prostaglandin D, E, and F synthases. J Lipid Mediat Cell Signal 12: 257-273, 1995.

6. Reiber H: Proteins in cerebrospinal fluid and blood: barriers, CSF flow rate and source-related dynamics. Restorative Neurol Neurosci 21: 79-96, 2003.

7. Jordan W, Hagedohm J, Wiltfang J, Laier-Groeneveld G, Tumani H, Rodenbeck A, Rüther E and Hajak G: Biochemical markers of cerebrovascular injury in sleep apnoea syndrome. Eur Respir J 20: 158-164, 2002

8. Hayaishi O: Molecular mechanism of sleep-wake regulation: a role of prostaglandin D2. Phil Tran R Soc Lond: 355: 275-280, 2000.

9. Matsumura H, Nakajima T, Osaka T, Satoh S, Kawase K, Kubo E, Kantha SS, Kasahara K and Hayaishi O: Prostaglandin D2-sensitive, sleep-promoting zone defined in the ventral surface of the rostral basal forebrain. Proc Natl Acad Sci USA 91: 11998-12002, 1994.

10. Satoh S, Matsumura H and Hayaishi O: Involvement of adenosine A2A receptor in sleep promotion. Eur J Pharmacol 351: $155-162,1998$

11. Sherin JE, Shiromani PJ, McCarley RW and Saper CB: Activation of ventrolateral preoptic neurons during sleep. Science 271: 216-219, 1996.

12. Åkerstedt T. Sömnbrist-ett hälsohot. In: H Wallskär and T Åkerstedt (eds). Goda Sömnboken. (Lack of Sleep-a Threat to Your Health. In: The Book for Good Sleep; In Swedish). Brombergs förlag AB, Nacka, pp12-19, 2008.

13. Westerlund $\mathrm{H}$, Alexanderson $\mathrm{K}$, Åkerstedt $\mathrm{T}$, Magnusson Hanson L, Theorell T and Kivimäki M: Work-related sleep disturbances and sickness absence in the Swedish working population, 1993-1999. Sleep 31: 1169-1177, 2008.

14. Socialstyrelsen. Folkhälsorapport 2009 (The National Board of Health and Welfare. Public health report 2009) [cited 2010, February 18] http://www.socialstyrelsen.se/Lists/Artikelkatalog/ Attachments/8495/2009-126-71_200912671.pdf

15. Kuster N, Balzano Q and Lin J: C. Mobile Communications Safety. Chapman \& Hall, London, 1997.

16. Hardell L, Carlberg M and Hansson Mild K: Epidemiological evidence for an association between use of wireless phones and tumor diseases. Pathophysiology 16: 113-122, 2009.

17. Oftedal G, Wilén J, Sandström M and Hansson Mild K Symptoms experienced in connection with mobile phone use. Occup Med 50: 237-245, 2000.

18. Sandström M, Wilén J, Oftedal G and Hansson Mild K: Mobile phone use and subjective symptoms. Comparison of symptoms experienced by users of analogue and digital mobile phones. Occup Med 51: 25-35, 2001.

19. IEGEMF: Independent Expert Group on Electromagnetic Fields. Recent Research on EMF and Health Risks. Swedish Radiation Protection Authority, ISSN 2000-0456, Report 36, 2009.
20. Borbély AA, Huber R, Graf T, Fuchs B, Gallmann E and Achermann P: Pulsed high-frequency electromagnetic field affects human sleep and sleep electroencephalogram. Neurosci Lett 275: 207-210, 1999.

21. Huber R, Graf T, Cote KA, Wittmann L, Gallmann E, Matter D, Schuderer J, Kuster N, Borbély AA and Achermann P: Exposure to pulsed high-frequency electromagnetic field during waking affects human sleep EEG. Neuroreport 11: 3321-3325, 2000.

22. Huber R, Treyer V, Borbély AA, Schuderer J, Gottselig JM, Landolt HP, Werth E, Berthold T, Kuster N, Buck A and Achermann P: Electromagnetic fields, such as those from mobile phones, alter regional cerebral blood flow and sleep and waking EEG. J Sleep Res 11: 289-295, 2002.

23. Regel SJ, Tinguely G, Schuderer J, Adam M, Kuster N, Landolt HP and Achermann P: Pulsed radio-frequency electro-magnetic fields: dose-dependent effects on sleep, the sleep EEG and cognitive performance. J Sleep Res 16: 253-258, 2007.

24. Arnetz B, Åkerstedt T, Hillert L, Lowden A, Kuster N and Wiholm C: The effects of $884 \mathrm{MHz}$ GSM wireless communication signals on self-reported symptom and sleep (EEG) - an experimental provocation study. PIERS Online 3: 1148-1150, 2007.

25. Hung CS, Anderson C, Horne JA and McEvoy P: Mobile phone 'talk-mode' signals delays EEG-determined sleep onset. Neurosci Lett 421: 82-86, 2007.

26. Valentini E, Curcio G, Moroni F, Ferrara M, De Gennaro L and Bertini M: Neurophysiological effects of mobile phone electromagnetic fields on humans: a comprehensive review. Bioelectromagnetics 28: 415-432, 2007.

27. Hamblin DL and Wood AW: Effects of mobile phone emissions on human brain activity and sleep variables. Int J Radiat Biol 78: 659-669, 2002.

28. Abdel-Rassoul G, El-Fateh OA, Salem MA, Michael A, Farahat F, El-Batanouny M and Salem E: Neurobehavioral effects among inhabitants around mobile phone base stations. Neurotoxicology 28: 434-440, 2007.

29. Kundi M and Hutter HP: Mobile phone base stations - effects on wellbeing and health. Pathophysiology 16: 123-135, 2009.

30. Söderqvist F, Carlberg M, Hansson Mild K and Hardell L: Exposure to an $890 \mathrm{MHz}$ mobile phone-like signal and serum levels of S100B and transthyretin in volunteers. Toxicol Lett 189: 63-66, 2009.

31. Wilén J, Johansson A, Kalezic N, Lyskov E and Sandström M: Psychophysiological tests and provocation of subjects with mobile phone related symptoms. Bioelectromagnetics 27 : 204-214, 2006

32. Jordan W, Tumani H, Cohrs S, Eggert S, Rodenbeck A, Brunner E, Rüther E and Hajak G: Prostaglandin D synthase (ßtrace) in healthy human sleep. Sleep 27: 867-874, 2004.

33. Pentreath VW, Rees K, Owolabi OA, Philip KA and Doua F: The somnogenic T lymphocyte suppressor prostaglandin D2 is selectively elevated in cerebrospinal fluid of advanced sleeping sickness patients. Trans R Soc Trop Med Hyg 84: 795-799, 1990.

34. Roberts II JL, Sweetman BJ, Lewis RA, Austen KF and Oates JA: Increased production of prostaglandin D2 in patients with systemic mastocytosis. N Engl J Med 303: 1400-1404, 1980.

35. Payne CA, Maleki S, Messina M, O'Sullivan MG, Stone G, Hall NR, Parkinson JF, Wheeler HR, Cook RJ, Biggs MT, Little NS, Teo C, Robinson BG and McDonald KL: Loss of prostaglandin D2 synthase: a key molecular event in the transition of a low-grade astrocytoma to an anaplastic astrocytoma. Mol Cancer Ther 7: 3420-3428, 2008.

36. Hardell L, Carlberg M and Hansson Mild K: Pooled analysis of two case-control studies on use of cellular and cordless telephones and the risk for malignant brain tumours diagnosed in 1997-2003. Int Arch Occup Environ Health 79: 630-639, 2006.

37. Hardell L and Carlberg M: Mobile phones, cordless phones and the risk for brain tumours. Int J Oncol 35: 5-17, 2009. 